\title{
Innovation: Love, Passion, or Both?
}

\author{
Nik Tehrani ${ }^{*}$, PhD; Jahan Ghofraniha ${ }^{2}, \mathrm{PhD}$; Cynthia Meckl-Sloan ${ }^{3}$ \\ 'DynoSense Academy \\ ${ }^{2}$ Northwestern Polytechnic University, ${ }^{3}$ Argosy University, USA
}

\begin{abstract}
Innovations are heavily influenced by both love and passion. First, innovation happens for the love of what one does, but passion keeps it going. Hence, it is through love and passion by which innovations are both born and nurtured. Human passions fuel innovations, and without these emotions, innovation would be impossible. Passionate innovators share their passion with others. (Int J Biomed. 2015;5(4):235-237.)
\end{abstract}

Keywords: Love; passion; innovation.

\section{Introduction}

There is an old saying that "necessity is the mother of invention." However, the question arises is how that necessity is formed and prioritized to inspire a solution. While an invention is the application of a new idea, it takes innovation to make it marketable. There are many tools for innovation, such as creating a culture that nurtures innovation, reducing the risk of sharing ideas, having constraints (price, time frame), and risk-aversion [1]. Innovation pioneers, like all innovators, have access to the same tools for innovation that all visionaries have access to, but some visionaries go beyond them to make a better world or by disrupting the current paradigm. Many innovative pioneers changed the future, first through invention followed by innovation.

Many innovators have gone beyond universal basic tools with imagination in their thinking. They have seen potential in the world that did not previously exist and harnessed technology to make it a reality, sometimes being successful and sometimes not. So, then, is it possible that the innovation of visionaries goes beyond basic tools and still have a strong motivation that keeps them going in the face of failures? Might there be another factor or factors that keep them on track until they reach their goals? Is it possible that love and passion are intangible factors that drive success?

Thomas Edison once remarked about his lengthy trial and error toward a working lightbulb that he had not failed, but rather "just found 10,000 ways that didn't work" [1]. Even

*Corresponding author: Nik Tehrani, PhD. DynoSense Academy, CA, USA.E-mail: ntehrani@dynosense.com before reaching 10,000 frustrating failing attempts, many potential innovators might have thrown up their hands and given up, but Edison's passion for finding the right electric lightbulb was stronger than his unsuccessful attempts. Nikola Tesla, who devoted all of his energy to science, is best known as the father of alternating current. He had many ideas that simply did not work the way he wanted them to, yet he kept on going. Tesla was also often ridiculed for suggesting inventions that seemed impossible, but, out of passionate belief that they would work, he invented them anyway [2].

Passion is the driving source on the road to success of startup companies and gives the ability to resist naysayers and stay focused in the face of adversity and failures. If one is not passionate about one's idea, how would he/she be able to successfully communicate the vision and mission of the company to others [3]? Passion is the fuel of the innovative fire and the burning desire to share that passion, but it's inadequate to just love the process; it is essential to have a burning desire to share that passion [4]. Tesla's Elon Musk shared his passion for electric cars by opening the company's technology patents to the automotive industry. According to Musk, Tesla could not conceivably manufacture electric vehicles quickly enough to alleviate the carbon crisis, so he allowed his company to embrace an open-source policy to provide entire industry with proprietary technology to fight the problem together [4].

Musk showed his entrepreneurial spirit early in his life. While a student attending the University of Pennsylvania, he paid his own tuition and expenses by converting his house into a party club and throwing huge parties. Musk went on later to invent Pay Pal, which he sold to eBay in 2002 for $\$ 1.5$ billion. Since then, Musk has used creating and innovating as his life's 
purpose by working an average of 100 hours a week. But is hard work what drives Musk toward innovation? [5]. It has been said that Musk is driven by ideas that promise to profoundly alter life today as we know it: space, clean energy and the internet. As a result, his passion has been to create businesses that focus on the commercialization of innovations that have impacted, or will impact all three [6].

Modern-day innovator, Steve Jobs changed the face of modern technology. In 1997, Jobs said, "Apple is not about making boxes for people to get their jobs done, although we do that well. Apple is about something more. Its core value is that we believe that people with passion can change the world for the better" [7]. The one quality of all successful entrepreneurs is that they don't do it for the money. They're passionate about their mission. [8]

Other innovators also have had a relationship with love and passion. Dan Bricklin, inventor of VisiCalc, known as the father of electronic spreadsheet, once said that unless one finds a true calling and love for the craft, the "risks may outweigh the rewards" [4]. It takes more than training or talent, because unless the timing is good, it isn't enough. An innovator needs to have a true passion for the challenges ahead and to be prepared for when the time is right for new ideas. Virgin Group's Richard Branson has said that "innovation begins with either a passion or a problem" [9]. Passion motivates innovation that, in turn, transforms that "passionate idea into a tangible business" [9]. Like Musk, Branson shares innovation with others. "Passions that lead to world-changing insights are rarely self-centered, navel-gazing activities" [9]. Instead, says Branson, sometimes the passions focus on making a positive effect for others.

Undeniably, the power of passion and love is immeasurable and unpredictable. There are no other forces that can be compared to their powerful hold on humans, but they are ignored in most scientific discussions. The language of science has evolved to make personal and subjective themes such as love and passion inconsequential [10]. But, is it through love or passion that human beings achieve the inspiration to innovate? Innovation has been described as doing what you love to do. But, can innovation also spring, not only from what one loves to do, but also from love felt for another human being?

Many innovations are centered on passion on love of humanity by creating medical breakthroughs that alleviate certain kinds of human suffering. The article "Monitor Diabetes From Your Smart Watch" [11] is the story of a father, John Costik, who, out of love for his young son, Evan who was diagnosed with type-I diabetes, altered a smart watch to help him monitor Evan's glucose. Costik and his wife had to keep tabs on Evan at 5 minute intervals because it was difficult to determine the correct dose of insulin for a meal's carbohydrate content, as Evan's blood sugar could shoot up or decrease drastically without warning. Costik and his wife were paranoid and afraid for Evan's life, which made the experience of the disease a lot more restricting for the boy. Not only was Evan missing out on many childhood pleasures, like the freedom to go outside and play, he was also under constant observation and was felt different from his friends.
Moreover, Costik and his wife could not keep watch on him every minute of every day, even though they tried. Even when Costik dropped Evan off at the daycare, he wanted school nurse check Evan's glucose level at all times and be alerted when it was progressing out of the acceptable range.

Costik, an engineer, came up with the innovative idea of connecting a Dexicom G4 CGM to a Motorola phone which uploaded all of his son's glucose information to a spreadsheet that viewable in Google with the help of a simple C\# program. This allowed the family to receive and monitor all of their son's health data, such as glucose levels, without having to be with him personally all the time. When Costik announced his innovation on Twitter, Lane Desborough, another dad whose child had diabetes, responded. Out of love for his son also, Desborough asked Costik for the C\# program and eventually developed Nightscout, a predictive system that could alert glucose levels by accessing essential information compiled in a database. Desborough made the software open-sourced out of love, so others could benefit from it. Desborough, Costik and others continued to collaborate, and in early 2014, they provided an Android app, Pebble watch, and Nightscout code open source, improving the code and making it easier to use.

Love is a strong emotion that motivates humans and has the power to influence physical change. Medical solutions are most often inspired by the innovator's experience with the disease or illness, just as in Costik's case. It was Costik's love for his son to give him as much of a normal life as possible, despite his condition that inspired him to invent a system which could provide his son with the freedom to live a normal life like other children without constant surveillance.

Long [9] correlates the commitment and dedication to get the job done to passion and love for the mission. "You only get out what you put in. It's easy to dedicate everything you have to something you love". He states that most failed ventures do not necessarily fail because of a bad idea but due to lack of passion in their mission. In 2005, Steve Jobs said in a Stanford commencement speech: "You've got to find what you love. The only way to do great work is to love what you do. If you haven't found it yet, keep looking. Don't settle. As with all matters of the heart, you'll know when you find it" [12]. Costik is a father who followed his heart through love to help improve his child's health through innovation, shared his idea, and had the passion to follow it through.

\section{Conclusion}

It is not enough to just have a lot of good innovative ideas for success. It also takes love for the journey of discovery and passion to make it happen. Love is an unstoppable force that can overcome pessimists and bring innovation to the brink of obsession. Finding love and passion to face and overcome the challenges of new ideas can result in the impossible becoming possible, just as Nikola Tesla, Thomas Edison, Steve Jobs, Elon Musk, Richard Branson, and John Costik were able to accomplish. In the end, the innovation must be shared for it to actually become a disruptor, like the electric light bulb, or become the foundation for further innovation, much like Costik's glucose monitor. 


\section{References}

1. Conway Management News. (2015). The innovator's dilemma. Retrieved from http://www.conwaymgmt.com/pdfs/ NL21-5-Innovation-NecessityIsTheMotherOfInvention.pdf

2. Earthlink. (2015). Some interesting facts about Nikola Tesla. Retrieved from http://home.earthlink.net/ drestinblack/ didyouknow.htm

3. Morris, L. "The Innovation Master Plan", from The CEO Guide to Innovation, Chapter 1, Special Edition for InnovationManagemen.com

4. Newquist, E. (2015). 7 characteristics of highly successful innovators. Retrieved from http://www.innovationexcellence. com/blog/2015/03/13/7-characteristics-of-highly-successfulinnovators/?Itemid=92\#sthash.jQYLcnO0.dpuf

5. Vance, A. (2015). Elon Musk. Inventing the future. Retrieved from http://www.mahindra.indiareads.com/ book/9780753555620/elon-musk-inventing-the-future/ biography-autobiography-general/

6. Innovation. (2015). Ordinary people change the world.
Retrieved from http://oninnovation.com/videos/detail. aspx ?video $=1258 \&$ title $=$ Ordinary People Change The World 7. Brainy Quotes. (2015). Steve Jobs. Retrieved from http:// www.brainyquote.com/quotes/authors/s/steve_jobs.html 8. Gregerson, H. (2015). How Richard Branson turned his passion into a tangible business. Retrieved from $\mathrm{http}$ ://fortune. com/2015/05/12/how-richard-branson-turned-his-passioninto-a-tangible-business/

9. Long, J. "7 Reasons rock star entrepreneurs hit home run after home run", Entrepreneur, June 15-2015

10. Gaines, S. (2001). Sex, love and science. Nature, 413(6853), 255. doi:http://dx.doi.org/10.1038/35095130

11. Costik, J. (2015). Monitor Diabetes From Your Smart Watch. Spectrum.ieee.org. Retrieved 27 June 2015, from http://spectrum.ieee.org/geek-life/hands-on/monitor-diabetesfrom-your-smart-watch/?utm_source=techalert\&utm medium $=$ email\&utm_campaign $=\overline{0} 52115$

12. Jobs, S. (2005). 'You've got to find what you love,' Jobs says. Commencement address. Stanford News.Retrieved from http://news.stanford.edu/news/2005/june15/jobs-061505.html 